\title{
Microstructure and Mechanism of Grain Raising in Wood
}

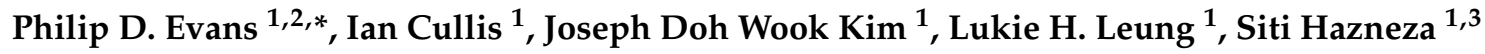 \\ and Roger D. Heady 4 \\ 1 Faculty of Forestry, University of British Columbia, Vancouver, BC V6T 1Z4, Canada; ian@bcnpha.ca (I.C.); \\ kdwace@hotmail.com (J.D.W.K.); mrlukieleung@gmail.com (L.H.L); hazneza@hotmail.com (S.H.) \\ 2 Centre for Wood Durability and Design Life, University of Sunshine Coast, Sunshine Coast QLD 4558, Australia \\ 3 Bioresource, Paper and Coatings Technology, School of Industrial Technology, Universiti Sains Malaysia, \\ Penang 11800, Malaysia \\ 4 Centre for Advanced Microscopy, Australian National University, Canberra ACT 0200, Australia; \\ roger.heady@anu.edu.au \\ * Correspondence: phil.evans@ubc.ca; Tel.: +1-604-822-0517; Fax: +1-604-822-9159
}

Received: 8 August 2017; Accepted: 24 August 2017; Published: 29 August 2017

\begin{abstract}
Grain raising, the lifting of fibres when water is applied to wood surfaces, is a reason why some companies are reluctant to finish wood products with water-borne coatings. However, the elements that lift-up and cause grain raising have not been identified, and the relationship between wood density and grain raising has not been clarified. Our work sought answers to both questions. We planed or sanded different woods using aluminum oxide abrasive paper, and characterized surfaces using profilometry and SEM. Surfaces were re-characterized after wetting and drying. Grain raising is inversely related to wood density. In particular, very low-density woods are highly susceptible to grain raising, whereas grain raising does not occur in high-density woods or planed woods. In low-density woods, sanding tears cell walls creating loosely-bonded slivers of wood that project from surfaces, particularly after wetting and drying. This mechanism for grain raising was confirmed by modelling the action of abrasives on wood cell walls using an array of hollow tubes and a serrated tool. Less commonly, fibres and fibre-bundles project from surfaces. We observed that grain raising was correlated with the coarseness of the abrasive and conclude that it can be reduced in severity by tailoring sanding to account for the density and surface microstructure of wood.
\end{abstract}

Keywords: wood; grain raising; sanding; water-borne coatings; fibres; slivers; confocal profilometry; scanning electron microscopy

\section{Introduction}

Grain raising, the lifting of fibres when water is applied to sanded wood surfaces, increases the roughness of wood, and is mentioned as one of the reasons why companies in North America are reluctant to finish wood products using water-borne coatings [1]. Grain raising can be avoided by finishing wood with solvent-based finishes [2], but this approach is becoming less acceptable due to environmental legislation limiting the solvent content of finishes [3]. Grain raising can be eliminated by lightly sanding wood to remove "fibres" projecting from surfaces [2,4], or its severity can be reduced by using modified finishes containing resins or hydrophobes [5-8]. Alternative approaches to reducing grain raising might be developed if the mechanisms responsible for the phenomenon were fully understood. However, there are only a handful of scientific papers on grain raising [9-12].

The first paper on grain raising by Koehler in 1932 used reflectance microscopy to examine the surface of planed or sanded mahogany (Swietenia sp.) and oak (Quercus sp.) woods, before and after wetting [9]. Koehler's images clearly revealed that increases in roughness of wood surfaces following 
wetting were more pronounced at sanded surfaces than planed surfaces, and also greater in oak than in mahogany [9]. Koehler claimed that increases in roughness were due to "fragments of fibres and pore wall projecting over the pores" at sanded wood surfaces [9]. However, his photographs were taken at low magnification (4:1) and it is not possible to see in his photographs if the woody element projecting from wood surfaces are fibre fragments, fibres, fibre bundles, or larger woody elements [9]. Higher magnification reflectance microscopy was used by Marra in his study of the factors responsible for grain raising of oak (Quercus sp.), and maple (Acer sp.) [10]. His observations suggested that fragments of thin-walled vessels, which are the conducting elements in oak and other hardwoods, projected from sanded oak surfaces after wetting and drying [10]. He also suggested that raised grain occurred due to swelling of the ridges between sanding scratches, and also as a result of the separation of fibres or groups of fibres that are attached at one end to sanded surfaces. Marra looked at the effects of wood structure and sanding variables on grain raising and concluded that wood structure, particularly grain angle, had a greater influence on the development of raised grain than sanding variables [10]. He also pointed out that the lack of a method of quantifying the raised grain was a problem [10]. This problem was overcome by Nakamura and Takachio in 1961 [11]. They used stylus profilometry to quantify the changes in roughness of wood following sanding and wetting. Roughness was defined as the difference in maximum peak and valley height in a $10 \mathrm{~mm}$ long profilometry traverse [11]. The roughness value of sanded wood surfaces after wetting minus the initial roughness was used as an index of gain raising. Nakamura and Takachios' profilometry results showed that grain raising was positively correlated with sanding pressure and coarseness of the abrasives used to sand wood surfaces [11]. Non-contact profilometry was used recently by Landry and coworkers to examine grain raising of yellow birch (Betula alleghaniensis Britt.) finished with water-based and solvent-based stains [12]. Their findings accorded with previous research, including our own unpublished research [13], indicating "that sanding method has an important role in grain raising generation".

To date each of the studies on grain raising has focused on only one or two species, with the exception of the work by Nakamura and Takachio in Japan that examined grain raising of seven wood species whose density varied from 0.37 to 0.71 [11]. However, their study did not find a relationship between density and grain raising, even though earlier work by Marra suggested that lower density springwood in oak was more susceptible to grain raising than summerwood [10]. Furthermore, the woody elements that rise up from sanded wood surfaces and are responsible for grain raising have not been precisely identified. In this paper, we seek to clarify the effects of wood density on grain raising and determine the microstructural feature responsible for grain raising. We hypothesize that the use of high-resolution profilometry and electron microscopy, in combination with physical modelling, will make it possible to answer these outstanding questions. Our ultimate aim is similar to those of Koehler [9] and Marra [10] who both sought to obtain a deeper understanding of the microstructure of grain raising to help develop better methods of selecting and machining wood to avoid the problem of grain raising.

\section{Materials and Methods}

\subsection{Effects of Sanding on the Grain Raising of Different Wood Species}

Preliminary research developed the experimental protocols for examining grain raising in different wood species. The species selected ranged from the lowest density wood species, such as quipo and balsa, through to the world's densest wood species, such as ebony and lignum vitae (Table 1). One wood sample for each species was obtained from UBC's xylarium (wood collection) and cut with a band saw to produce specimens measuring $\sim 20 \mathrm{~mm}$ (wide) $\times 80 \mathrm{~mm}$ (long) $\times 20 \mathrm{~mm}$ (thick) with their growth rings oriented tangentially to their wide faces. Samples were selected at random and hand-sanded along the grain using 120 and 180 grit aluminium oxide abrasive papers ( $30 \mathrm{~s}$ each). 
Table 1. Wood species used for an experiment that examined the relationship between wood density and grain raising.

\begin{tabular}{|c|c|c|c|}
\hline Name & Code & $\begin{array}{l}\text { Density } \\
\left(\mathrm{kg} / \mathrm{m}^{3}\right)^{*}\end{array}$ & $\begin{array}{c}\text { Growth Rings and } \\
\text { Texture [14] }\end{array}$ \\
\hline Quipo (Cavanillesia platanifolia, Humb. \& Bonpl.) Kunth & Q & 118 & Diffuse porous \\
\hline Balsa (Ochroma pyramidale, Cav. ex Lam.) Urb. & $\mathrm{B}$ & 133 & Diffuse porous \\
\hline Obeche (Triplochiton scleroxylon, K. Schum.) & A & 226 & Diffuse porous \\
\hline Western red cedar (Thuja plicata, Donn ex D. Don) & WR & 263 & Medium/coarse \\
\hline Agarwood (Aquilaria spp.) & AG & 265 & Diffuse porous \\
\hline Redwood (Sequoia sempervirens, D. Don) Endl. & $\mathrm{R}$ & 329 & Coarse \\
\hline Grand fir (Abies grandis, Dougl. ex D. Don) Lindley & $\mathrm{F}$ & 348 & Medium/coarse \\
\hline Western hemlock (Tsuga heterophylla, Raf.) Sarg. & WH & 350 & Medium/fine \\
\hline Ponderosa pine (Pinus ponderosa, Dougl.) ex Lawson & PP & 351 & Medium/coarse \\
\hline White spruce (Picea glauca, Moench) Voss) ex Lawson & WS & 372 & Medium/fine \\
\hline Black spruce (Picea mariana, Mill.) Britt., Sterns \& Poggenburg & BS & 376 & Medium/fine \\
\hline Red alder (Alnus rubra) Bong. & RA & 381 & Diffuse porous \\
\hline Black cottonwood (Populus trichocarpa, Torr \& Gray ex Hook. F.) & $\mathrm{BC}$ & 386 & Diffuse porous \\
\hline Huon pine (Lagarostrobos franklinii, Hook) Quinn & $\mathrm{HP}$ & 400 & Fine \\
\hline Mahogany (Swietenia macrophylla) King & $\mathrm{M}$ & 412 & Diffuse porous \\
\hline Douglas fir (Pseudotsuga menziesii, Mirb.) Franco & DF & 449 & Medium/coarse \\
\hline Black cherry (Prunus serotina) Ehrh. & $\mathrm{CB}$ & 461 & Diffuse porous \\
\hline Mountain ash (Eucalyptus regnans) F. Muell. & MA & 484 & Diffuse porous \\
\hline Black walnut (Juglans nigra) L. & WB & 488 & Semi-ring porous \\
\hline Lodgepole pine (Pinus contorta) Dougl. & LP & 511 & Medium/fine \\
\hline Teak (Tectona grandis) L.f. & TE & 526 & Semi-ring porous \\
\hline Tamarack (Larix laricina, Du Roi) K. Koch & TA & 553 & Medium/fine \\
\hline American beech (Fagus grandifolia) Ehrh. & $\mathrm{BE}$ & 564 & Diffuse porous \\
\hline Yellow birch (Betula alleghaniensis) Britt. & YB & 583 & Diffuse porous \\
\hline Hickory (Carya spp.) & $\mathrm{H}$ & 585 & Semi-ring porous \\
\hline Red stinkwood (Prunus africana, Hook. f.) Kalkman & RS & 590 & Diffuse porous \\
\hline Red oak (Quercus rubra) L. & $\mathrm{RO}$ & 605 & Ring porous \\
\hline Sugar maple (Acer saccharum) Marsh. & $\mathrm{SM}$ & 659 & Diffuse porous \\
\hline Ironwood (Xylia xylocarpa Roxb.) Taub. & IW & 694 & Semi-ring porous \\
\hline Rasberry jam (Acacia acuminata) Benth. & RJ & 814 & Diffuse porous \\
\hline Red ironbark (Eucalyptus sideroxylon,A. Cunn. ex Woolls) & RI & 834 & Diffuse porous \\
\hline Banga wanga (Amblygonocarpus obtusangulus, Welw. ex Oliv.) Exell \& Torre & BW & 896 & Diffuse porous \\
\hline Ebony (Diospyros spp.) & E & 1011 & Diffuse porous \\
\hline Lignum vitae (Guaiacum officinale) L. & LV & 1170 & Diffuse porous \\
\hline
\end{tabular}

${ }^{*} N=1$. Therefore, standard deviations for density of individual samples are not included in the table.

A sanded sample was placed on the $x-y$ stage of a non-contact surface profilometer (Cotec Altisurf 500 , Altimet, Alpespace, Grenoble, France). The elapsed time between sanding and surface analysis was approximately $5 \mathrm{~min}$. An area measuring $16 \times 4 \mathrm{~mm}^{2}$ was scanned with a $300 \mu \mathrm{m}$ probe using the following measurement parameters: spacing between measurement points, $7 \times 7 \mu \mathrm{m}^{2}$; scan speed $=1 \mathrm{~mm} / \mathrm{s}$; total scan time for each sample was $3 \mathrm{~h} 12 \mathrm{~min}$. The software Papermap (Altimet, Alpespace, Grenoble, France) was used to level surfaces and remove form, calculate the roughness of sanded surfaces, and produce images of surfaces [15]. Following initial surface analysis, distilled water was applied as a droplet to the surface of each sanded sample using a micropipette $\left(35 \mu \mathrm{L} / \mathrm{cm}^{2}\right)$. Each droplet was drawn across the surface of the sample using a thin sheet of plastic. After $3 \mathrm{~min}$ the water was gently wiped off the sample using a cotton cloth. The sample was air dried in a conditioning room at $20 \pm 1{ }^{\circ} \mathrm{C}$ and $65 \% \pm 5 \%$ r.h. (relative humidity) for $16 \mathrm{~h}$ and its surface roughness was re-measured, as above. These procedures were repeated until the initial (dry) and final (dry/wet/dry) roughness of all samples were measured. Grain raising was calculated as the difference in average surface roughness $\left(S_{a}\right)$ of samples before and after wetting and drying. The basic density of all wood species was assessed on separate irregularly-shaped wood blocks cut from parent samples. The wood blocks were oven-dried at $105^{\circ} \mathrm{C}$ overnight, placed in a desiccator over silica gel for $10 \mathrm{~min}$, and then weighed on an analytical balance. Samples were then vacuum-impregnated with distilled water and left to soak in water for one week. The volume of the water-saturated samples was measured using an Archimedean volume-displacement method. Basic density was calculated as oven dry weight $(\mathrm{kg})$ / green volume $\left(\mathrm{m}^{3}\right)$. 


\subsection{Grain Raising of Sanded versus Planed Wood}

A sub-set of the 34 wood species examined above were used to further explore the grain raising of different wood species, and also the influence of surfacing methods on grain raising. The species selected were: Balsa, western red cedar, black cherry, sugar maple, and lignum vitae. Air-dried wood samples of different sizes were obtained from UBC's xylarium or purchased commercially. Forty samples were examined (eight for each of the five species). Samples were sanded (as above) or planed using a disposable stainless steel microtome blade (Type S35, Feather Safety Razor Co., Osaka, Japan) attached to a blade holder (Type 130A, Feather Safety Razor Co., Osaka, Japan) and clamped to the stage of a microtome (Spencer Lens Co., Buffalo, NY, USA). A fresh blade was then inserted into the blade holder and each specimen was replaned to produce a clean surface. Sanded or planed samples were placed on the $x-y$ stage of a profilometer and the roughness of the samples before and after wetting and redrying was measured as above. The software Papermap was used to calculate the roughness parameters of five regions $\left(0.2 \times 0.2 \mathrm{~mm}^{2}\right)$ within each scanned area. Following the initial surface analysis, a droplet of distilled water was applied to the surface of each of the sanded and planed samples using a micropipette, as above. Each sample was air-dried and its surface roughness was re-measured, as above. These procedures were repeated until the dry and wet roughness of all samples was measured ( 5 species $\times 8$ samples $\times 2$ surface types $\times 5$ replicate roughness measurements $=400$ measurements in total). Analysis of variance was used to examine the effect of fixed (species and surface preparation) and random factors on grain raising, calculated as the difference in roughness of samples before and after wetting and drying. Statistical computation was performed using Genstat (version 18.2, VSN International, Hemel Hempstead, UK). Before the final analysis, diagnostic checks were performed to determine whether data conformed to the underlying assumptions of analysis of variance, i.e., normality with constant variance. These assumptions were confirmed using residual plots produced by Genstat. Significant results $(p<0.05)$ are plotted on graphs and error bars $(p<0.05)$ on graphs, which were derived from Fisher's least significant difference (LSD) test [16], can be used to compare differences between individual means. Sanded and planed samples were also examined using scanning electron microscopy to better understand the microstructural features responsible for grain raising. Samples were attached to separate aluminium stubs using nylon nail polish and coated with a $10 \mathrm{~nm}$ layer of gold to make them electrically conductive. A scanning electron microscope fitted with a high brightness lanthanum hexaboride electron source (Cambridge Stereoscan 360, Leica Microsystems, Wetzlar, Germany) or a variable pressure scanning electron microscope (S-2600N, Hitachi Ltd., Tokyo, Japan) was used to obtain images of the tangential surfaces of samples after sanding or planing, and again after wetting and drying [17]. Loose material present at sanded or planed surfaces, both before and after wetting, was removed using transparent tape, and the tape was mounted on aluminium stubs and imaged using a scanning electron microscope, as above.

\subsection{Physical Modelling of Grain Raising}

Marra commented that the "abrasive action of the grits on wood surfaces is difficult to visualize" [10]. We faced the same difficulty when trying to interpret images of sanded wood surfaces before and after wetting and drying. Furthermore, models of the ploughing action of abrasives on metals were not helpful because wood is softer than most metals, and is porous, unlike metals [18]. However, physical models of wood have been developed in the past to aid understanding of its complex three-dimensional microstructure [19]. We made a similar physical model and simulated the abrasive action of mineral grits on wood using a serrated metal tool. The model was made simply to visualize the abrasive action of mineral grits on the microstructure of wood fibres. The model was made from an $8 \times 4$ array plastic tubes each measuring $257.2 \mathrm{~mm}$ (length) $\times 7.1 \mathrm{~mm}$ (diam.) Plastic tubes were bonded together using a fast-setting epoxy adhesive. The model was fixed to a horizontal benchtop and a serrated metal tool (https:/ / www.kuglers.com/kitchen/cuisipro-julienne-peeler) was pressed down on the surface of the model and drawn across the surface of the uppermost layer of 
plastic tubes. Photographs of the surface of the model were taken using a digital single-lens reflex (DSLR) camera (Canon 5D Mark II-Canon Inc., Tokyo, Japan) mounted on a tripod.

\subsection{Effects of Abrasive Size on Grain Raising of Maple Panels}

Twelve maple veneer faced panels purchased from a commercial retailer (P.J. White, Vancouver, $B C$, Canada) were each cut into four samples measuring $150 \mathrm{~mm} \times 280 \mathrm{~mm}$. Samples were levelled with an 80 grit aluminum oxide belt and then finish-sanded with 120, 120/150, or 120/150/180 grit aluminium oxide abrasive belts using a wide-belt sander (Unisand K 1350 M3, SCM Group, Rimini, Italy) with a feed speed of $7 \mathrm{~m} / \mathrm{s}$. The roughness of sanded samples was measured using profilometry, as above. Water was then applied to an area (as above) on the surface of the samples and they were then conditioned overnight at $20 \pm 1{ }^{\circ} \mathrm{C}$ and $65 \% \pm 5 \%$ r.h. The roughness of the samples was re-measured using profilometry. Grain raising was calculated as the difference in roughness of sanded samples before and after wetting and drying. Analysis of variance for a randomized block design was used to examine the effect of grit size on grain raising of samples [20]. Wood samples sanded with different abrasive papers, before and after wetting and drying, were also examined as above using a field emission scanning electron microscope (Hitachi S-4700, Hitachi Ltd., Tokyo, Japan).

\section{Results}

The difference in surface roughness of the various wood species after sanding and wetting and air drying, hereafter referred to as grain raising, is shown in Figure 1. There are large differences in the grain raising of the different wood species. Some of the denser woods show no grain raising, whereas grain raising is much more pronounced in lower density species. There is a significant $(p<0.001)$ inverse relationship between grain raising and the density of the different woods, but the proportion of the variance in grain raising that is explained by density is modest $\left(R^{2}=0.44\right)$, because there is significant deviation between observed and fitted values. For example, grain raising of the world's lowest density wood species, quipo $(Q)$, is much higher than predicted from linear regression. There was a stronger and more linear relationship between the logarithm $(\ln )$ of density and grain raising.

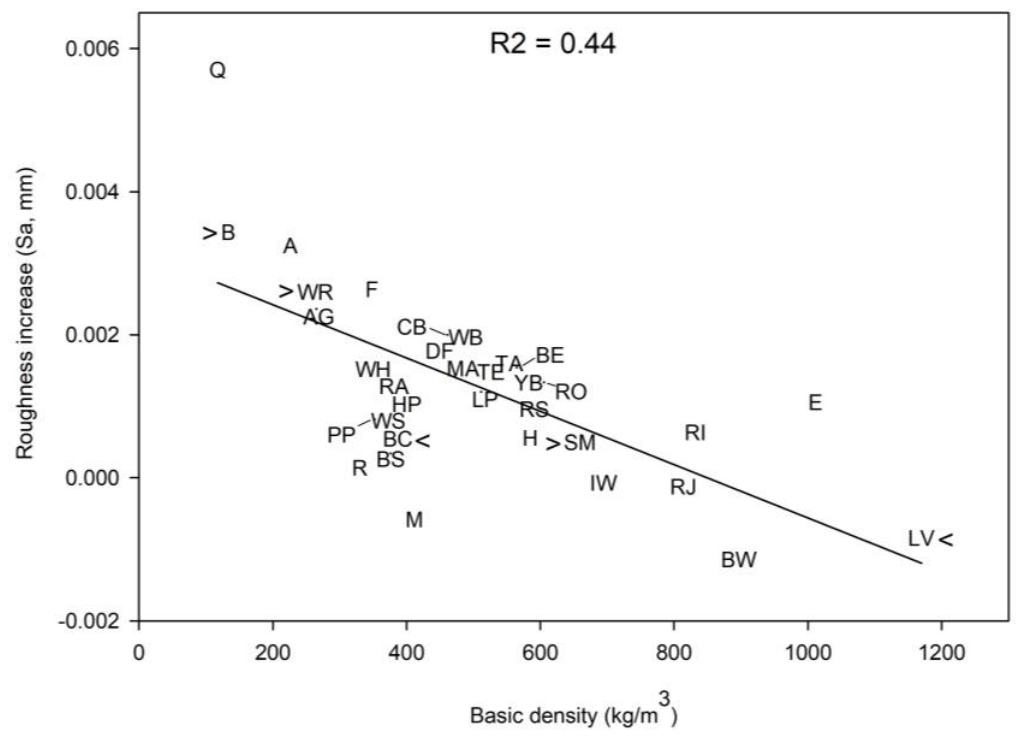

Figure 1. Relationship between density of woods and grain raising defined as the increase in surface roughness after sanding and wetting and air drying. Wood species can be identified using the abbreviations in Table 1. Values for roughness increases of some wood species were similar and their abbreviations overlapped. In these cases the precise numerical values for roughness increases are indicated by a period (.). In four cases an oblique line is drawn from the period to the abbreviated species name. 
The five species arrowed in Figure 1 were examined in more detail to explore the effects of "species" and surfacing methods on grain raising. These species span almost the entire natural range of wood densities and include balsa (B), western red cedar (WR), black cherry (BC), sugar maple (SM) and lignum vitae (LV). Grain raising of the lowest density woods (balsa and western red cedar) is significantly $(p<0.05)$ greater than those of higher density woods (black cherry and sugar maple) and, particularly, lignum vitae, which showed no grain raising (Figure 2). Analysis of variance indicated that the main effects of wood species (S), surface preparation (SP), and the interaction of $\mathrm{S} \times \mathrm{SP}$ $(F(4,383)=11.01, p<0.001)$ were statistically significant $(p<0.001)$. The latter interaction occurred because there is no significant difference $(p>0.05)$ in the grain-raising of the higher density sanded wood samples and the planed wood samples (Figure 2).

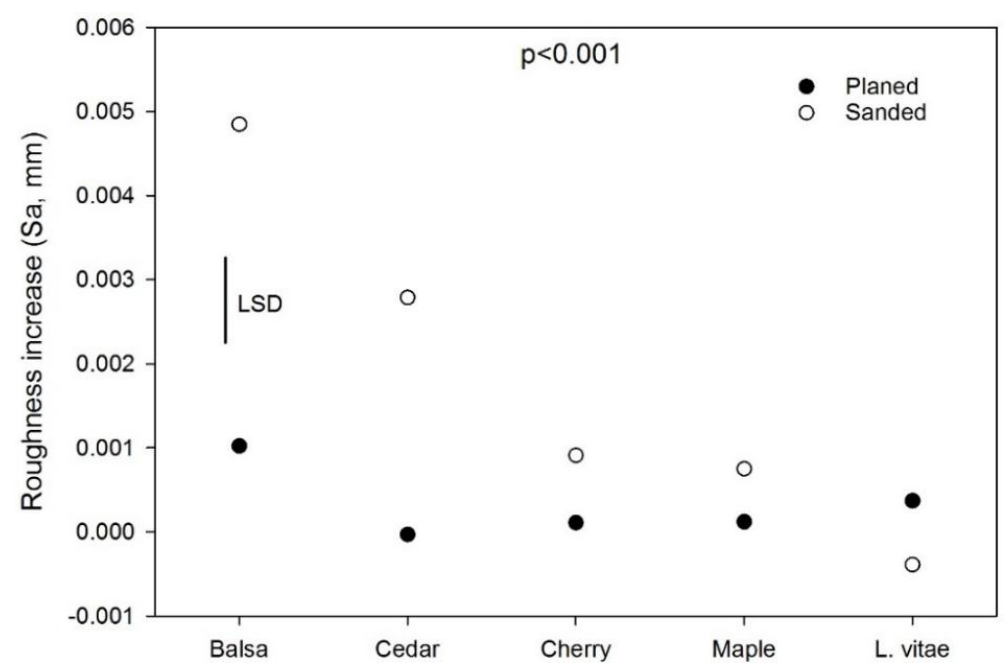

Figure 2. Grain raising of sanded and planed wood surfaces. Differences in roughness that exceed the length of the error bar (LSD) are statistically significant $(p<0.05)$.

Confocal profilometry images of samples after sanding and wetting and redrying are shown in Figure 3. In all sanded samples (Figure 3a,c,e,g) there are ridges of material, and in balsa there are strips that are elevated above the ridges and oriented at an angle to the ridges (Figure 3a). Confocal profilometry images of sanded surfaces after wetting and drying are shown in Figure $3 \mathrm{~b}, \mathrm{~d}, \mathrm{f}, \mathrm{h}$. Strips of material oriented at an angle to the ridges are present in all samples (except lignum vitae, Figure $3 \mathrm{~h}$ ), although they are most obvious in balsa (Figure 3b). These strips are elevated above the surface of the samples. The microstructure of these strips and the effects on sanding and planing on the structure of wood surfaces was examined using scanning electron microscopy (SEM) (Figures 4-7).

Figure 4 shows SEM images of balsa wood. Sanding of balsa created a mat of degraded cell wall material that obscured the underlying anatomical features of the wood (Figure 4a). This mat consisted of slivers of cell wall material that were mainly aligned in the fibre direction, although some slivers were bent and aligned tangentially to fibres (Figure 4a). These slivers were attached at one end to their parent fibres and there was a greater tendency for them to project vertically from the surface following wetting and drying (Figure $4 \mathrm{~b}$ ). In contrast, it was possible to see the underlying structure of balsa wood in the planed surface after wetting and drying, although there is evidence that planing caused tearing of fibre walls and the torn material projected from planed balsa wood surfaces (Figure 4c). Figure $4 \mathrm{~d}$ shows cell wall fragments removed from a sanded balsa wood surface following wetting and drying. The material removed from the surface consisted of long slivers of cell wall material, and much smaller fragments. Far less material was removed from the surface of planed balsa wood following wetting and drying. 


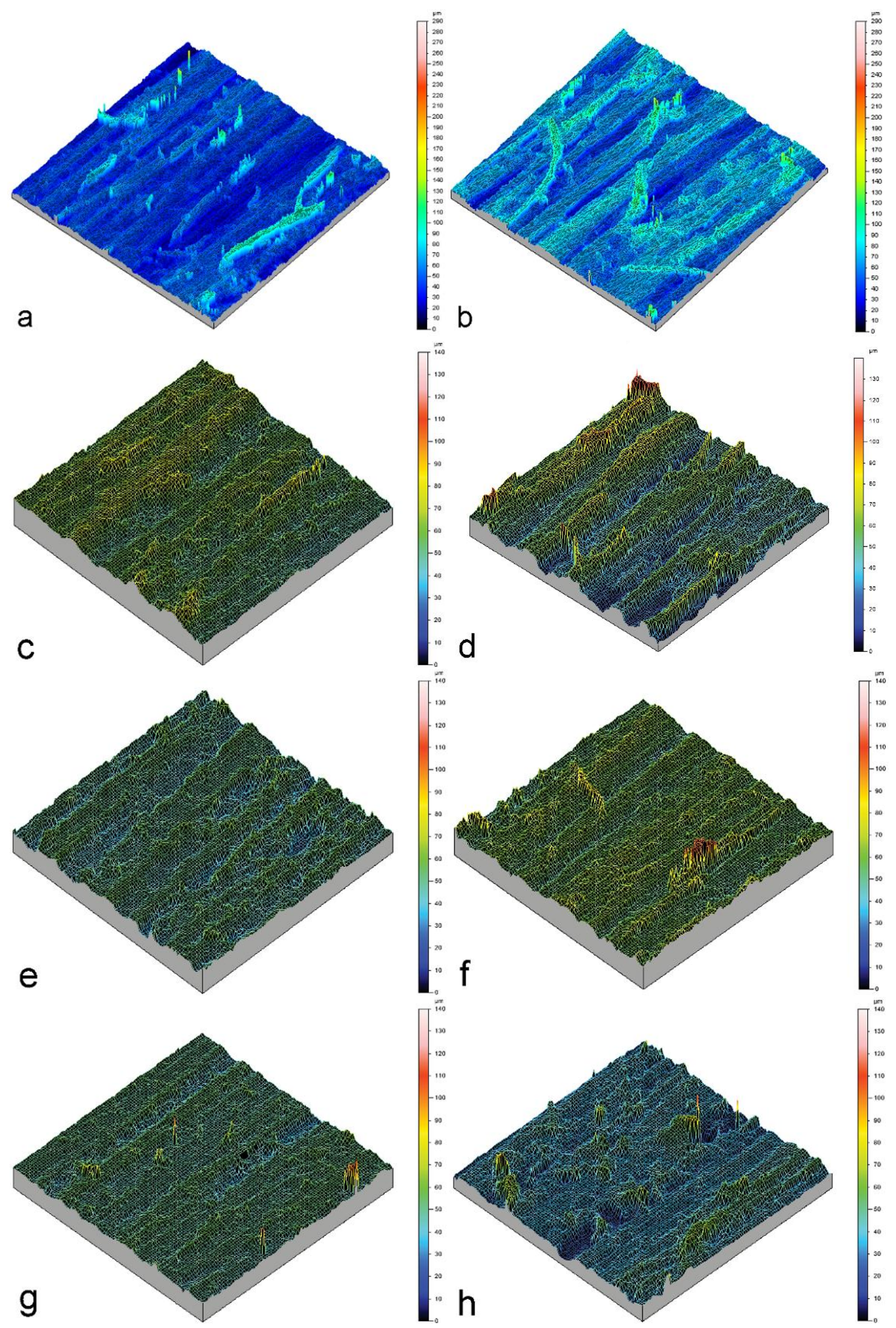

Figure 3. Confocal profilometry images of sanded surfaces before $(\mathbf{a}, \mathbf{c}, \mathbf{e}, \mathbf{g})$ and after grain raising $(\mathbf{b}, \mathbf{d}, \mathbf{f}, \mathbf{h})$ : (a,b) balsa; (c,d) western red cedar; (e,f) black cherry; $(\mathbf{g}, \mathbf{h})$ sugar maple. 

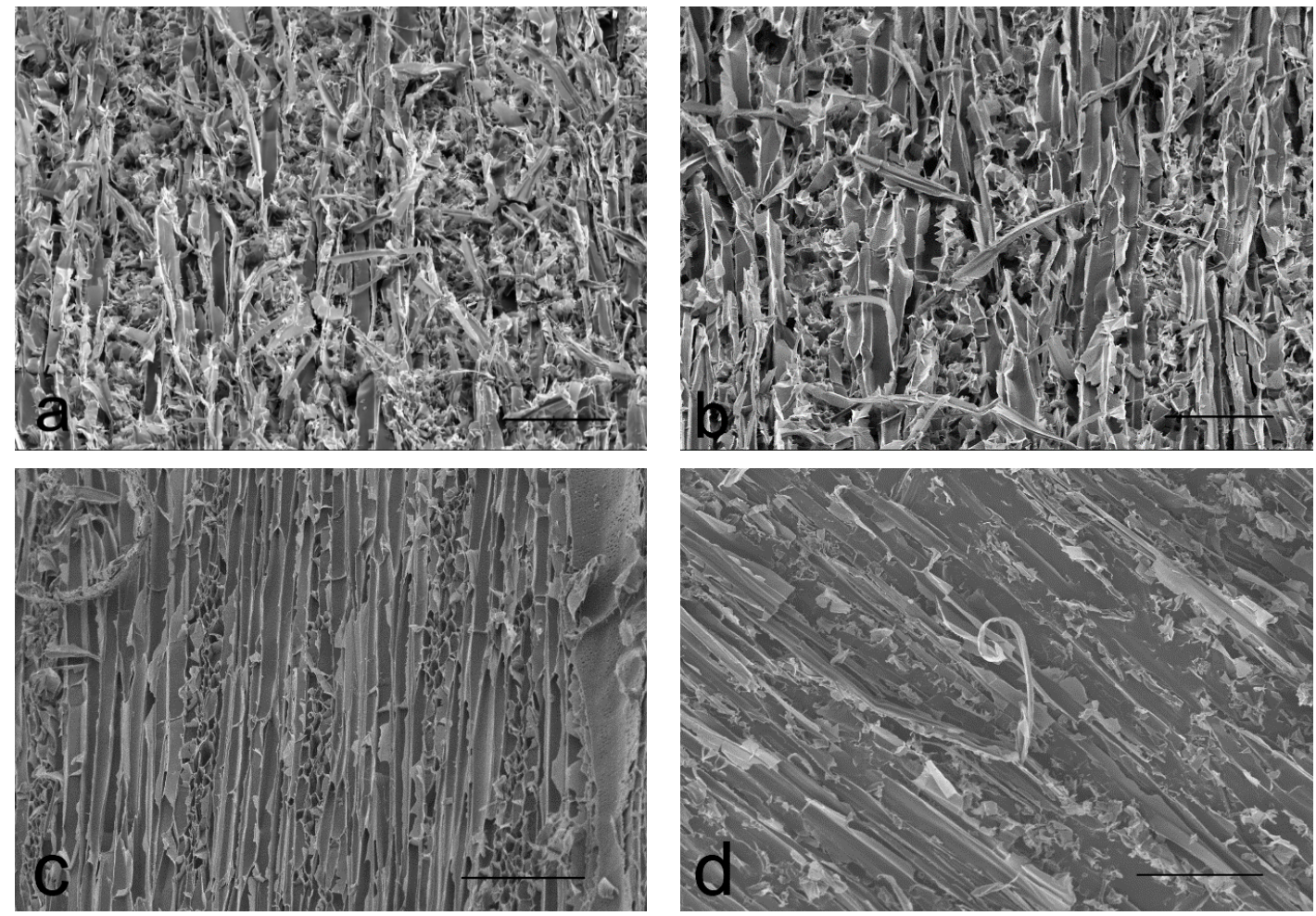

Figure 4. Balsa wood surfaces: (a) surface after sanding with 120 and 180 grit aluminium oxide abrasive papers; (b) sanded surface after wetting and redrying; (c) planed surface after wetting/redrying; and $(\mathbf{d})$ loose surface material removed from $(\mathbf{b})$ using transparent tape. Scale bars $=200 \mu \mathrm{m}$.

Sanding of western red cedar surfaces left cell wall material attached to the vertical walls of tracheids that appeared as ridges in confocal profilometry images (Figure 5a). This material is more obvious in the sample that was wetted and then dried (Figure 5b). In this sample, you can see ribbons or slivers of cell wall material that are bent-over and projecting from the wood surface. They are absent from the planed surface (Figure $5 \mathrm{c}$ ), but are easily seen in the photograph that shows the cell wall material removed by tape testing (Figure $5 \mathrm{~d}$ ).

Sanding of sugar maple surfaces also left slivers of cell wall material attached to the underlying wood, although they are smaller than those observed on sanded balsa or cedar surfaces (Figure 6a). Sanding of maple surfaces created grooves at the surface of the wood, in addition to slivers of wood attached to cell walls. These slivers of wood projected from wood surfaces after wetting and drying (Figure 6c), as was observed at balsa and western red cedar surfaces. In addition, we observed hollow tubular elements projecting from maple surfaces indicating that "fibre rise" contributed to grain raising in maple. Maple surfaces showed little damage as a result of planing and very little material was removed by tape testing. In contrast, the tape removed a variety of different materials from maple wood that had been subjecting to the sanding and the grain raising procedure, including parts of thin-walled vessel elements containing helical windings, parts of fibres and cell wall slivers, and smaller debris (Figure 6d).

Sanding did not create loosely-bonded cell wall material at the surface of lignum vitae wood, in contrast to its effects on balsa, cedar, cherry, and maple. Instead sanding created a series of grooves at the surface of the wood (Figure 7a). The surface was largely unchanged after the grain-raising procedure (Figure $7 \mathrm{~b}$ ), and very little material was removed from lignum vitae by tape testing (Figure 7d). Lignum vitae is the world's densest wood and is very difficult to section, which accounts for why the surface of the planed lignum vitae sample is uneven (Figure 7c). 

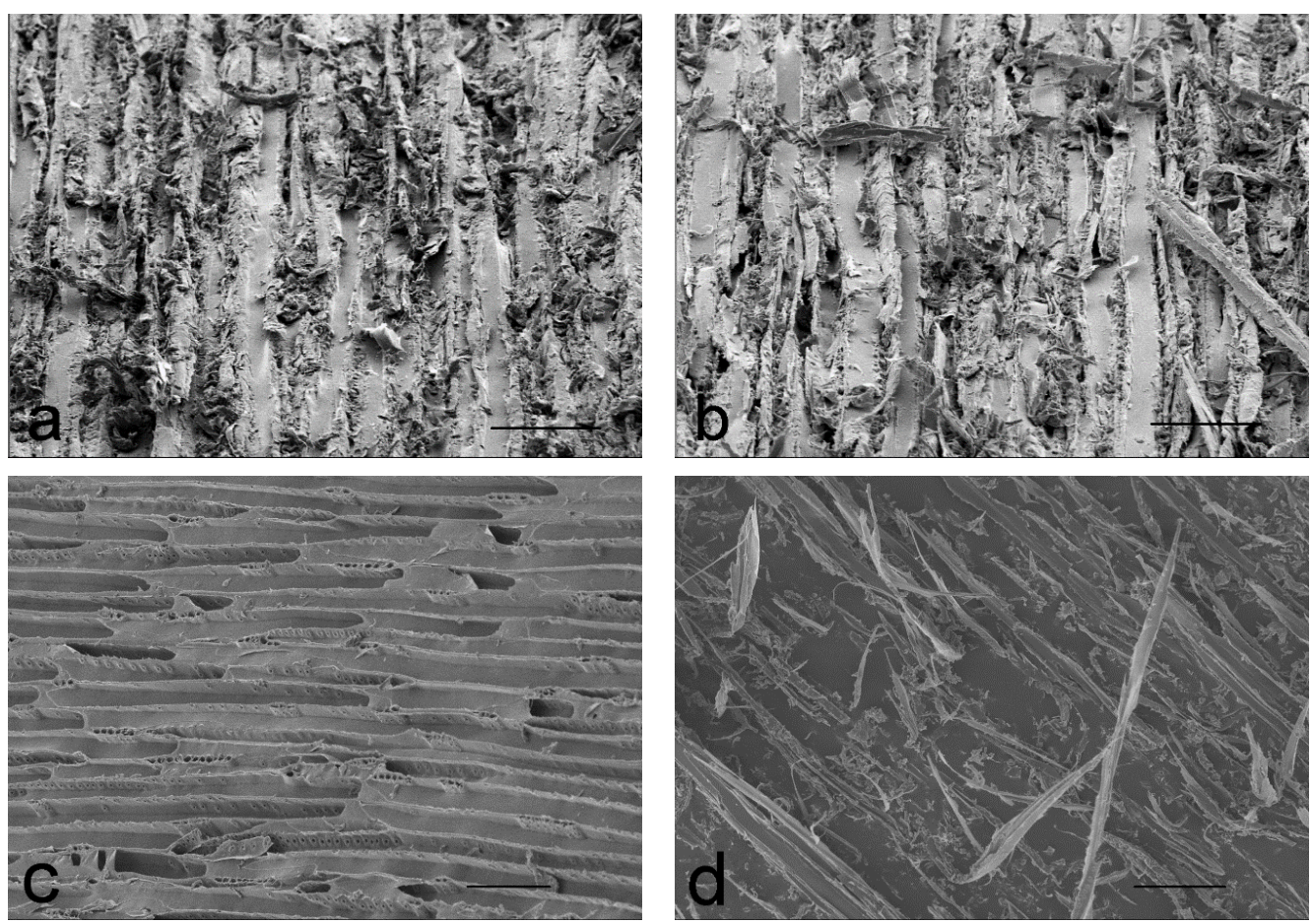

Figure 5. Western red cedar wood surfaces after: (a) sanding; (b) sanding and wetting/redrying; (c) planing/wetting/redrying; and (d) material removed from (b) using transparent tape. Scale bars $=100 \mu \mathrm{m}$.
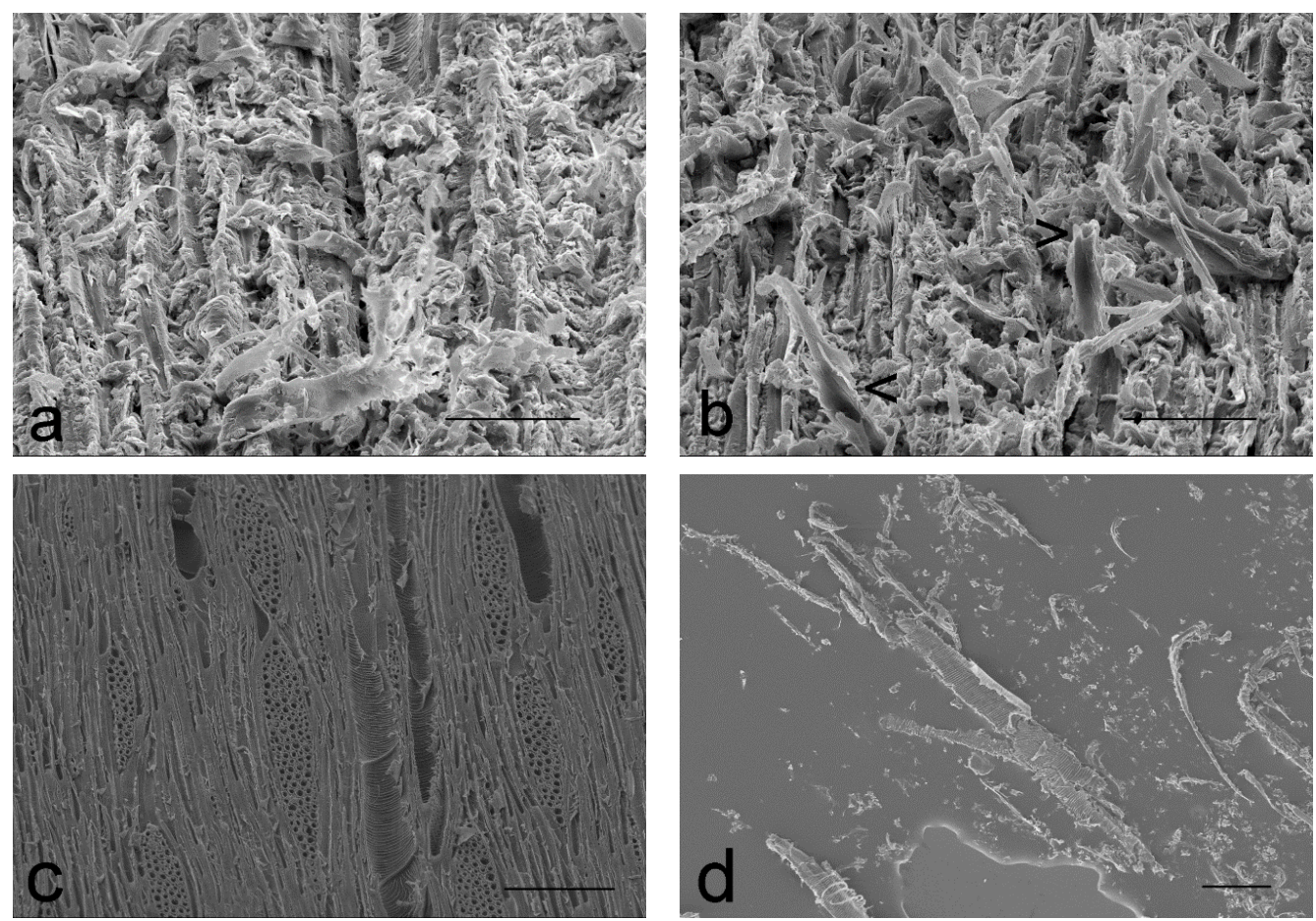

Figure 6. Sugar maple wood surfaces after: (a) sanding; (b) sanding/wetting/redrying; (c) planing/ wetting/ redrying; and (d) material removed from (b) using transparent tape. Scale bars $(a, b)=50 \mu \mathrm{m}$; $(\mathrm{c}, \mathrm{d})=100 \mu \mathrm{m}$. 

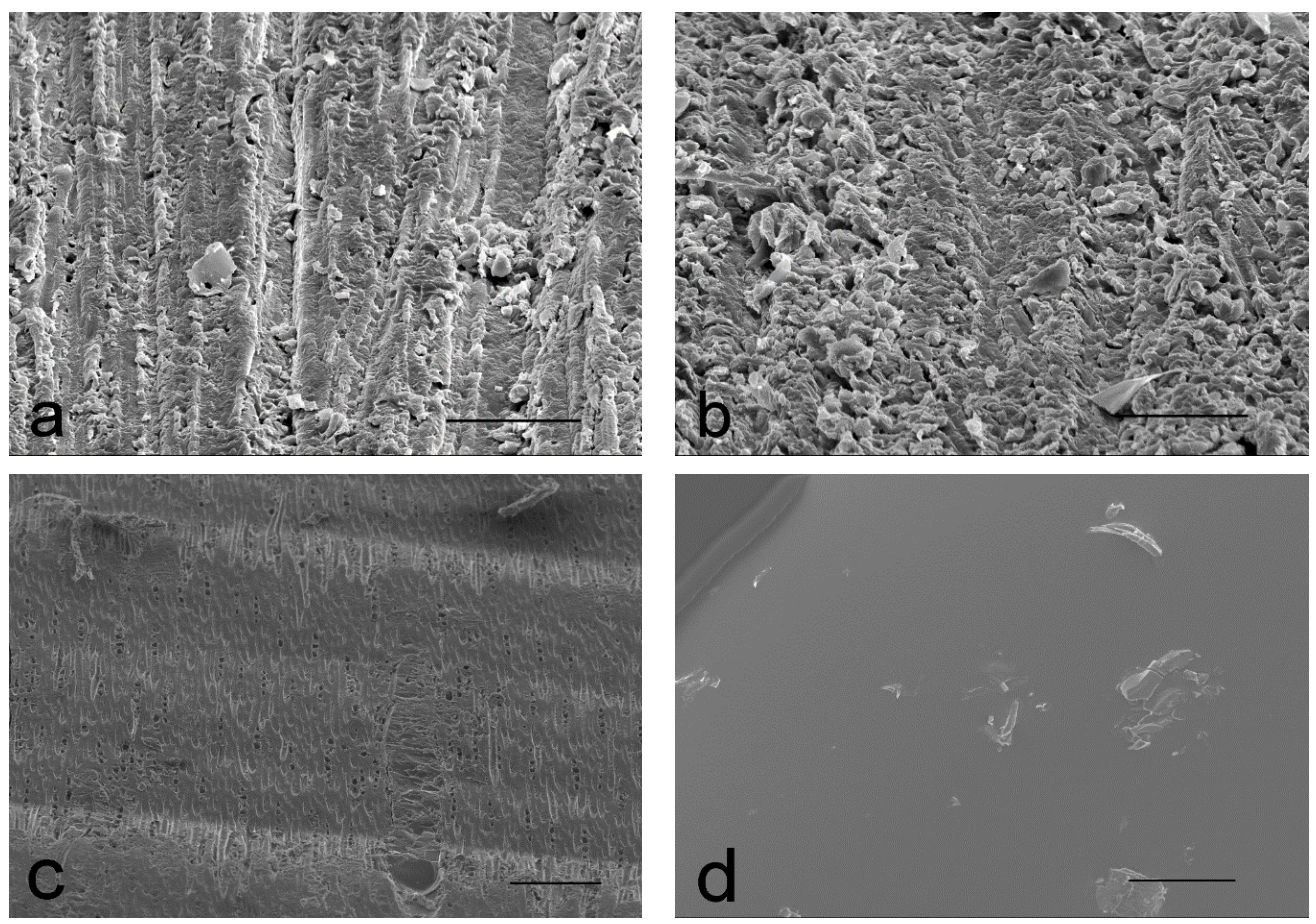

Figure 7. Lignum vitae wood surfaces after: (a) sanding; (b) sanding/wetting/redrying; (c) planing/ wetting/ redrying; and (d) material removed from (b) using transparent tape. Scale bars $(a, b)=50 \mu m$; $(\mathrm{c}, \mathrm{d})=100 \mu \mathrm{m}$.

Our observations of grain raising (above) on sanded wood samples were complemented by physical modelling of the effects of sanding on wood surfaces. Arrays of plastic tubes modelled the porous microstructure of wood and a serrated tool drawn across the tubes simulated the abrasive action of sandpaper on the microstructure of wood (Figure 8). The serrated tool completely removed parts of the uppermost layer of plastic tubes when it was drawn across the surface of the tubes. It also created strips of plastic that were still attached to the sides of the tubes (Figure 8). These strips projected above the surface of the uppermost layer of tubes, and were oriented in the direction of the tubes, or at an angle to the tubes (depending on the width and length of the strips, Figure 8).

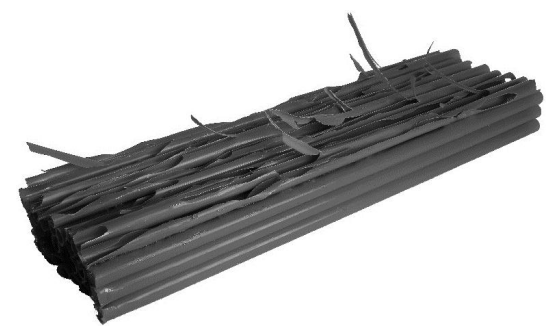

Figure 8. Tubular plastic wood model after a serrated tool was drawn across its surface.

Our observations of grain raising of wood described above were carried out on hand-sanded solid wood samples. These observations are relevant to small craft-based industries that employ hand sanding of solid wood. However, larger industrial facilities use machine-sanding and often process composite panels with a decorative face veneer in addition to solid wood. Therefore, we examined grain raising of maple veneer-faced panels that were machine-sanded. There was a significant effect of sanding on grain raising $(F(2,22)=5.15, p=0.015)$ and a positive relationship between abrasive size and grain raising (Figure 9$)$. In other words, sanding with finer abrasives (150 and 180 grit) resulted in significantly $(p<0.005)$ less grain raising than sanding with a coarser abrasive (120 grit). 
Scanning electron microscopy was used to examine the surface structure of maple veneer-faced panels after sanding and then again after wetting and drying. Sanding with 120 grit abrasive paper created grooves and ridges, and loosely-bonded material at the surface of the veneer (Figure 10a). After wetting and drying a variety of woody material projected from the sanded surface (Figure 10b) including slivers of wood cell wall (arrowed left), ends of fibres (arrowed right of centre), and bundles of fibres (arrowed extreme right). Sanding surfaces with abrasive paper with finer abrasive grits caused progressively less damage to the wood surface, and there was less grain raising after wetting and drying (Figure 10c,d). These observations accord with measurements of the differences in roughness of surfaces after sanding and wetting and drying (Figure 9).

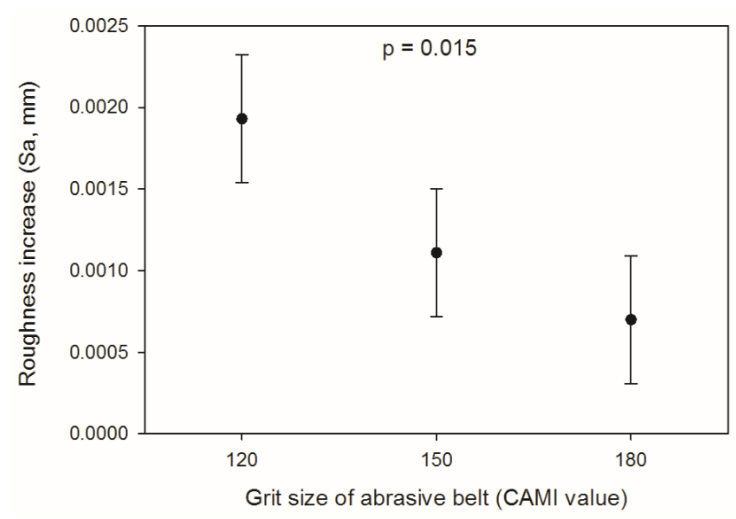

Figure 9. Effect of grit size of abrasive belts on the grain raising of maple veneer-faced panels sequentially sanded using an industrial wide belt sander.
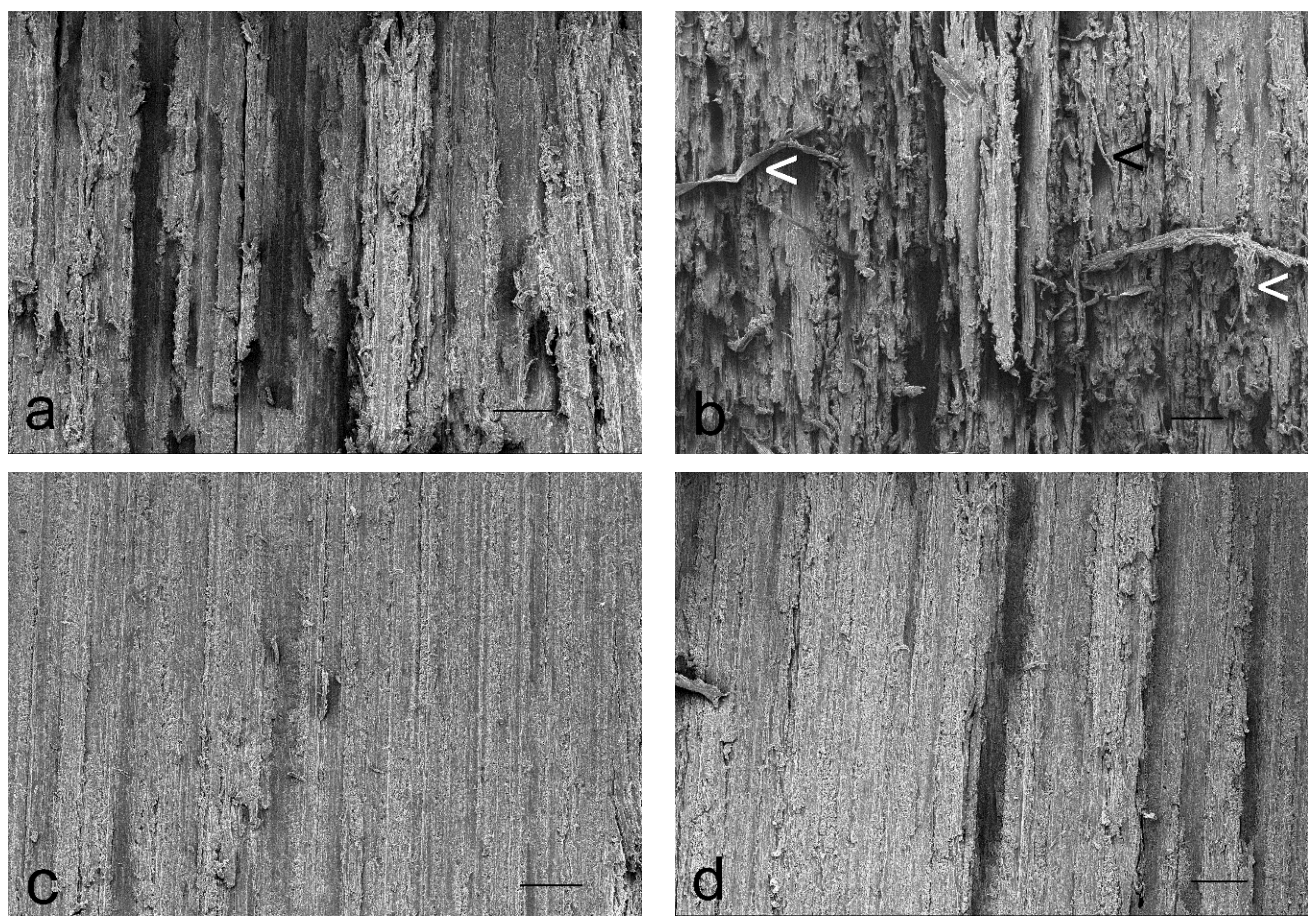

Figure 10. Appearance of maple veneer surfaces after composite veneer-faced panels were sanded with an industrial wide belt sander: (a) surface sanded with 120 grit aluminum oxide belt; (b) surface sanded with 120 grit aluminum oxide belt and then subjected to grain raising procedure; (c) surface sanded with 120/150/180 grit aluminum oxide belts; and (d) surface sanded with 120/150/180 grit aluminum oxide belts and then subjected to the grain raising procedure. Scale bars $=250 \mu \mathrm{m}$. 


\section{Discussion}

Our results show an inverse relationship between the density of wood species and grain raising, and suggest a mechanism to account for this relationship. In low-density wood species, such as balsa and western red cedar, "fibres" are thin walled and are easily perforated and shredded during sanding resulting in the formation of slivers of cell walls that are loosely bonded to the underlying wood surface. These slivers, which were also formed when we modelled the effects of abrasives on a tubular wood model, project from wood surfaces after sanding and also to a greater extent after surfaces become wet and then dry. This phenomenon was observed under ambient conditions using confocal profilometry, and also under low vacuum scanning electron microscopy. The phenomenon appears to account for grain raising in low-density wood species. In the highest density wood species, such as lignum vitae, sanding did not create slivers of cell wall material and grain raising did not occur. Grain raising occurred in species whose density fell between those of balsa and lignum vitae, for example, sugar maple, and can be explained in part by the mechanism we have just proposed, particularly the shredding of thin-walled vessel elements. In addition, the partial detachment of fibres and fibre bundles also appears to contribute to grain raising in maple. However, we find little evidence that swelling of ridges created by the ploughing effect of abrasive particles during sanding contributes to grain raising because such ridges were prominent in higher-density species that did not develop significant grain raising.

The mechanism for grain raising we have proposed helps to explain some of the results of previous studies that examined grain raising. For example, the relationships between grain raising and abrasive size observed by Nakamura and Takachio [11], and also here, may be explained by the increased ability of larger abrasive grains to slice open fibre walls leaving partially-detached slivers of wood at sanded surfaces. Increased sanding pressure might produce a similar effect, as observed by Nakamura and Takachio [11], because there would be more intimate contact between abrasive particles and cell walls. The observations by Marra [10] that species such as oak are susceptible to grain raising may be explained by the presence of abundant large and thin-walled earlywood vessel elements that are more easily shredded during sanding than thicker-walled fibres. Evidence here for such an effect was the presence of shredded vessel walls in the debris removed from sanded hardwoods. Sanding wood at an oblique angle to fibres results in greater grain raising according to Marra [10], possibly because it would increase the partial shredding of fibres along their length, creating more slivers of wood that are partially attached to the underlying wood.

Our results confirm the observations of Koehler [9] that sanding can create a surface that is susceptible to grain raising, because grain raising was present in sanded wood surfaces and absent from carefully-matched wood samples that had been planed. However, grain raising was minimal in maple that was sanded with an industrial-scale (wide-belt) sander using 120, 150, and 180 grit abrasive belts. This finding suggests that grain raising can be minimized by using a sanding sequence that is tailored to particular wood species. Low-density wood species, or ones that possess an abundance of thin-walled cells, for example, ring porous species such as oaks, may benefit from an additional finer sanding step. However, fine sanding reduces the ability of stains and dyes to colour wood [21] and this would need to be taken into account when deciding whether to introduce a final fine sanding step to reduce grain raising in lower-density woods. Other alternatives, as suggested by the patent literature, include the use of stains containing binders that presumably bond projecting woody slivers to the underlying wood and make them easier to remove using denibbing and inter-coat sanding steps [5-8].

Our research sheds no light on whether grain raising occurs when water is applied to wood surfaces or when it subsequently dries. Marra [10] suggested that grain raising occurred during the wetting phase as wood elements swell and presumably curl away from the underlying wood surface. This suggestion is supported by unpublished industry observations. The alternative, that curling of wood elements occurs during drying, is supported by observations of the tendency of pulp fibres to curl during drying [22]. This issue would benefit from further research to measure the moisture-induced strains that develop when sanded wood surfaces become wet and then dry. Further research is also 
needed on the grain raising of medium-density fibreboard (MDF), which is a problem when products made from MDF are finished with water-borne coatings. This is a fertile area for industrially-important research and the approaches used here to better understand grain raising of solid wood could provide insights into the grain raising of MDF and possibly other wood composites that are commonly finished with water-borne coatings.

\section{Conclusions}

We have shown that there is an inverse relationship between the density of wood species and grain raising, and have suggested a mechanism to account for this relationship. This mechanism helps to explain why some wood species are more susceptible to grain raising than others, and how some sanding parameters influence grain raising. Our results suggest that grain raising can be minimized by tailoring sanding to particular wood species for example using finer sanding step with lower density species that are susceptible to grain raising. However, research is needed to fully explore the benefits and costs of developing species-specific sanding schedules to minimize the grain raising of wood finished with water-borne coatings.

Acknowledgments: We thank Natural Resources Canada (Value-to-Wood Program) and the Canadian Foundation for Innovation for their financial support. Philip D. Evans thanks Viance, Tolko, FPInnovations, Faculty of Forestry (UBC) and the Government of British Columbia for their support of the BC Leadership Chair in advanced forest products manufacturing technology at the University of British Columbia. None of the organizations acknowledged here were involved in the design of our experiments, collection, and interpretation of data, or the writing of this paper.

Author Contributions: Philip D. Evans conceived and designed the experiments; Ian Cullis performed grain raising experiments and profilometry; Philip D. Evans and Roger D. Heady imaged wood surfaces using SEM; Siti Hazneza, Joseph Doh Wook Kim, Lukie H. Leung, and Philip D. Evans conceived and carried out physical modelling of grain raising; Philip D. Evans analysed all data and wrote the first draft of the paper; and all authors discussed and commented on the results and contributed to the final submitted and published manuscript.

Conflicts of Interest: The authors declare that they have no affiliations with or involvement with organizations that have financial interests in the subject matter or materials discussed in this paper.

\section{References}

1. Vandivort, T.F.; Osborn, L.E.; Hassler, C.C. Waterborne Wood Finishing Technology as an Alternative to Solventborne Products to Achieve Compliance with Volatile Organic Compound (VOC) Emissions Regulation; Appalachian Hardwood Center Fact Sheet; Appalacian Hardwood Center: Morgantown, WV, USA, 1993.

2. Bush, E.R. Wood Stain. U.S. Patent 2,000,121, 7 May 1935.

3. Challener, C. Trends in Interior Wood Coatings: Tracking the Shift from Solvent to Waterborne and UV. Available online: http:/ / www.paint.org/article/trends-in-interior-wood-coatings-tracking-the-shift-fromsolvent-to-waterborne-and-uv/ (accessed on 25 August 2017).

4. Folsom, J.K. Raising the grain. Rocky Mt. Rev. 1981, 35, 270. [CrossRef]

5. Rippey, H.F; Dike, T.W. Process for Treatment of Porous Materials and Product Thereof. U.S. Patent 2,150,188, 14 March 1939.

6. Eastland, J. Wood Finishing Composition Consisting of Methylmethacrylate Resin and Borax. U.S. Patent 2,829,067, 1 April 1958.

7. Burwell, J.S. Method of Staining Wood and Composition Therefor. U.S. Patent 3,311,484, 28 March 1967.

8. Beane, B.E.; Safta, E. Wood Pretreatment for Water-Based Finishing Schedules. U.S. Patent 5,512,323, 30 April 1996.

9. Koehler, A. Some observations on raised grain. Trans. Am. Soc. Mech. Eng. 1932, 54, 27-30.

10. Marra, G.G. An analysis of the factors responsible for raised grain on the wood of oak following sanding and staining. Trans. Am. Soc. Mech. Eng. 1943, 65, 177-185.

11. Nakamura, G.-I.; Takachio, H. An experiment on the roughness and stability of sanded surface. Mokuzai Gakkaishi 1961, 7, 41-45.

12. Landry, V.; Blanchet, P.; Cormier, L.M. Water-based and solvent-based stains: Impact on the grain raising in yellow birch. Bioresources 2013, 8, 1997-2009. [CrossRef] 
13. Evans, P.D.; Cullis, I. Reducing Grain Raising during the Finishing of Wood with Water-Borne Coatings; Unpublished Value to Wood (Natural Resources Canada, Ottawa, Canada) Report, No. UBC13; Natural Resources Canada: Ottawa, ON, Canada, 2009; p. 54.

14. Panshin, A.J.; Zeeuw, C.D. Textbook of Wood Technology; McGraw-Hill Book Co.: New York, NY, USA, 1980.

15. Anon. Data Characterization Workstation, Altisurf ${ }^{\circledR}$ 50. Available online: http://www.hoskinscientifique. com/uploadpdf/Instrumentation/Altimet/hoskin_DT\%20A50\%20TV_US_corrige_471cdf31c57e4.pdf (accessed on 26 August 2017).

16. Williams, L.J.; Hervé, A. Fisher's least significant difference (LSD) test. In Encyclopedia of Research Design; Salkind, N., Ed.; SAGE: Thousand Oaks, CA, USA, 2010; p. 6.

17. Evans, P.D.; Haase, J.G.; Seman, A.S.B.; Kiguchi, M. The search for durable exterior clear coatings for wood. Coatings 2015, 5, 830-864. [CrossRef]

18. Larsen-Badse, J. Influence of grit size on the groove formation during sliding abrasion. Wear 1968, 11, 213-222. [CrossRef]

19. Lachenbruch, B. Physical models as an aid for teaching wood anatomy. Int. Assoc. Wood Anat. J. 2011, 32, 301-312. [CrossRef]

20. Evans, P.D.; Vollmer, S.; Kim, J.D.W.; Chan, G.; Kraushaar Gibson, S. Improving the performance of clear coatings on wood through the aggregation of marginal gains. Coatings 2016, 6, 66. [CrossRef]

21. Flexner, B. Understanding Wood Finishing: How to Select and Apply the Right Finish; Fox Chapel Publishing: East Petersburg, PA, USA, 2010; p. 308.

22. De Roever, E.D.W.F.; Cosper, D.R. Fibre rising and surface roughening in lightweight coated paper-An environmental scanning electron microscopy study. Scanning 1996, 18, 500-507. [CrossRef]

(C) 2017 by the authors. Licensee MDPI, Basel, Switzerland. This article is an open access article distributed under the terms and conditions of the Creative Commons Attribution (CC BY) license (http:/ / creativecommons.org/licenses/by/4.0/). 